\title{
Strategic human resource management and inertia in the corporate entrepreneurship of a multinational enterprise
}

\section{Joe J. Amberg ${ }^{a}$ \& Sara L. McGaughey ${ }^{b}$}

andependent scholar, Meilen, Switzerland; ${ }^{b}$ Griffith Business School, Griffith University, Australia

Contact: Sara McGaughey, s.mcgaughey@griffith.edu.au

\begin{abstract}
Corporate entrepreneurship (CE) supports sustained competitive advantage through the continuous exploration and exploitation of new sources of knowledge. With an emphasis on combining knowledge in new configurations, strategic human resource management (HRM) activities are core to these entrepreneurial endeavours. We explore how strategic HRM activities may facilitate and impede corporate entrepreneurship through a rich, qualitative case study of three local entities within a business unit of a large multinational enterprise facing business stagnation and low levels of corporate entrepreneurship. Responding to a call for more empirical research that probes the subtle and complex interactions between HRM activities and other organisational factors affecting CE, we identify a configuration of interdependent factors that mutually reinforce each other and sustain inertia in corporate entrepreneurship. We also make two novel contributions to theory by (1) elaborating the links between organisational process-orientation, strategic HRM and CE; and (2) refining to our current understanding of human competencies for CE.
\end{abstract}

Key words: Corporate entrepreneurship, strategic human resource management, multinational enterprise, process-orientation, exploration, exploitation, managerial entrepreneurship 


\section{Introduction}

Corporate entrepreneurship supports sustained competitive advantage through the continuous exploration and exploitation of new sources of knowledge. It is the process whereby an individual or a group of individuals, in association with an existing organisation, create a new business venture within or outside that organisation, or instigate renewal or innovations within the existing organisation - including innovations in products, business models and internal processes (Kuratko and Audretsch 2009, 2013; Kuratko, Hornsby and Hayton 2015; Sharma and Chrisman 1999). This involves combining new and existing knowledge into novel configurations. It is thus not surprising that strategic human resource management (HRM) with an emphasis on human capital development and related firm-specific capabilities (Wright, Dunford and Snell 2001; Wright and McMahon 1992, 2011) - is core to the success of such entrepreneurial endeavours. Interest in the relationship between HRM activities and corporate entrepreneurship (CE) began to emerge around three decades ago (e.g. Kuratko, Montagno and Hornsby 1990; Schuler 1986). It is only in the past decade, however, that it has gained momentum, prompting extensive literature reviews (Hayton 2005; Hayton, Hornsby and Bloodgood 2013), theorisation (e.g. Chadwick and Dabu 2009; Hayton and Kelley 2006), and empirical research (Kaya 2006, Montoro-Sánchez and Ribeiro 2011). Despite this growing interest and activity, our understanding of how strategic HRM influences corporate entrepreneurship remains fledgling (Tang, Wei, Snape and Ng 2015).

In this paper, we respond to calls for more qualitative, empirical studies to deepen our understanding of the relationship between strategic HRM and corporate entrepreneurship in firm-specific contexts (Chadwick and Dabu 2009; Hayton et al 2013). Specifically, we present a rich, qualitative case study of entities within the Fire Safety Business Unit Siemens AG. Siemens AG is widely considered an industrial conglomerate and one of the oldest companies among the top global players, being ranked 40th in the Global 500 Fortune list of 2010. In the five years prior, however, the firm showed significant symptoms of business stagnation, 
relative to major competitors. In 2009, Siemens' top management identified a severe lack of entrepreneurship throughout the company as a critical issue. 'Local entrepreneurship' was defined as a new key action in the strategic planning of 2010 to 2014. Our study of three local entities within the Fire Safety Business Unit of Siemens thus represents an instrumental case (Stake 1995) that can offer potentially novel insights into how HRM activities can both support and undermine efforts to foster $\mathrm{CE}$ in a large multinational enterprise (MNE). Hence, we ask:

How do human resource management practices serve to overcome, or potentially sustain, inertia in the low level of corporate entrepreneurship within the Fire Safety Business Unit of Siemens AG?

In capturing the real-world complexity in the relationship between strategic HRM activities and corporate entrepreneurship across a multi-unit firm, our analysis supports earlier suggestions that a bundle of 'fits' are necessary for CE success (Ireland, Covin and Kuratko 2009; Kuratko, Hornsby and Goldsby 2004). However, rather than success, we identify a configuration of inter-dependent factors that mutually reinforce each other and sustain inertia in low levels of corporate entrepreneurship. We also make two novel contributions to theory. First, we identify and elaborate the links between an organisational process-orientation, strategic HRM and CE. Second, we refine our current understanding of human competencies (Hayton and Kelley 2006, Wright and McMahon 2011) for CE. We thus respond directly to recent calls for empirical research that probes the subtle and complex interactions between HRM activities and other organisational factors affecting CE (Chadwick and Dabu 2009, Hayton et al 2013).

\section{Theoretical Background}

\section{Corporate Entrepreneurship}

Corporate entrepreneurship is increasingly seen as essential to long term growth and sustainability, but remains elusive for many firms. It can be understood as the successful search for, and exploitation of, entrepreneurial opportunities arising from information and knowledge 
asymmetries related to markets or technologies (Ireland et al. 2009). A central theme within the literature on $\mathrm{CE}$ is the distinction between the exploration of entrepreneurial opportunities and the exploitation of those opportunities selected, in the quest for both entrepreneurial and Ricardian rents (Chadwick and Dabu 2009). Entrepreneurial rents flow from the unique abilities of individuals and firms to anticipate, exploit and create market disequilibria, such as emerging opportunities to market products or services. In contrast, Ricardian rents accrue from owning an economically valuable factor of production that has inelastic supply (Teece, Pisano and Shuen 1997), such as differences in the quality of human resources. They can also arise from heterogeneity that is not intrinsic to the strategic factor, but evolves over time - such as complex and causally ambiguous social relations that underpin effective teamwork (Chadwick and Dabu 2009; McGaughey and Liesch 2002).

Research seeking to identify factors that foster entrepreneurship in established companies identify a number of recurrent themes. The most common aspects include the importance of appropriate organisational structures, which included loose intra-organisational boundaries (Antoncic and Hisrich 2001), reduction in bureaucratic barriers, and flexible policies and procedures of companies (Kuratko et al. 1990). Recognition of entrepreneurial achievements based on appropriate reward or incentive systems is also important (Fry 1987, Brazeal 1993, Hayton 2005), along with an entrepreneurial firm culture incorporating a willingness for change, shared goals of innovation, trust, freedom granted for entrepreneurial action, forgiveness for failures, and management proactivity towards innovation (Hayton 2005, Menzel, Aaltio and Ulijn 2007). Top management support by explicitly provided sponsorships and coaching is typically seen as key, as is the provision of adequate resource slack and avoidance of excessive controls and bureaucracy (Dess et al. 2003), relevant training and team building, and appropriate communication means and knowledge exchange both internally and externally (Birkinshaw and Hood 2001, Christensen 2005). Finally, the importance of a long 
term focus to foster entrepreneurial action and the acceptance and management of risk is stressed (Fry 1987).

Integrating a variety of elements in the above discussion, Ireland and colleagues (2009, p. 39) suggest that a 'bundle of fits' between the different elements of a CE strategy "are necessary for CE success". Recognising different 'bundles of fits' according to internal and external contingencies point to the context-specific nature of CE endeavours and outcomes. Indeed, it is increasingly recognised that $\mathrm{CE}$ activities within corporations, their antecedents and outcomes are heterogeneous, and that we need to know more about this variety (Hayton et al., 2013; Nason, McKelvie and Lumpkin 2015; Phan, Wright, Ucbasaran and Tan 2009). Rather than building more abstract, integrative frameworks based on prior studies, this observation points to the importance of more qualitative studies that allow for emergent, unanticipated insights across different contexts (Chadwick and Dabu 2009, Hayton et al 2013).

\section{Strategic HRM and CE}

The field of strategic HRM is devoted to exploring HRM's role in supporting business strategy in the pursuit of competitive advantage (Wright, Dunford and Snell 2001; Wright and McMahon 1992, 2011). Many of the above factors supporting CE - such as an appropriate organisational culture - are shaped by HRM activities, including recruitment and selection, development and rewards systems, and training. Chadwick and Dabu (2009) argue that HRM takes on strategic significance by supporting the 'accretion, coordination and exploitation of knowledge' in the within firms in a process they call 'managerial entrepreneurship' (p. 254). Formal managerial entrepreneurship is directed by decision makers through HRM systems, where sets of HRM activities can guide knowledge generation, coordination and utilisation within the firm. In contrast, informal managerial entrepreneurship arises from workers' discretionary efforts. HRM activities can be used to build up intra-organisational contexts favourable to coordinating and utilising the dispersed knowledge held by employees for CE, 
and thus also influence informal managerial entrepreneurship. Thus, HRM activities - whether undertaken by a formal HRM department or elsewhere - function as the 'firm's strategic infrastructure by generating and leveraging the entrepreneurial knowledge needed to sustain a firm's competitive advantage over time' (Chadwick and Dabu 2009, p. 264).

Hayton and colleagues $(2005,2013)$ provide two of the most comprehensive reviews of the relationship between CE and HRM to date, based on similar assumptions of the centrality of knowledge and learning to CE. Their model also assumes that internal and external knowledge exchange essential to opportunity exploration and exploitation is underpinned by social capital and trust, as is the risk-taking behaviour necessary in the high uncertainty context of CE (Brockhaus 1980; Ling, Simsek, Lubatkin and Veiga 2008; Petrakis 2005). Synthesising a large body of literature, Hayton (2005) identified the importance of socialisation and teamoriented training involving members from different functional areas; job designs that allow for autonomy and discretionary behaviours; high levels of perceived support from top management that often manifest in the form of resource availability, and appropriate (often intrinsic) rewards and incentives. A long term career orientation that favours retention has also been identified as important, as well as rewards systems that consider the longer term (Morris et al. 1993; Schuler 1986) and reward outcomes rather than conformity to pre-defined plans (Chadwick and Dabu 2009). Organisational culture that promoted discretionary, informal behaviours that lie at the heart of $\mathrm{CE}$ and that eschew tight controls was also found to be relevant. Formal HRM practices play a key role in sustaining such cultures conducive to CE, and thus promote both formal and informal managerial entrepreneurship (Chadwick and Dabu 2009, Hayton 2005, Hayton et al 2013).

Overarching, integrative frameworks of the role HRM may play in fostering CE, while invaluable to synthesising a growing body of literature, have typically overlooked the potentially important distinction between exploration and exploitation, and the specific human capital involved or required. For example, teamwork and a tolerance for risk are advocated for 
$\mathrm{CE}$, but does this apply equally to all engaged across the various roles undertaken in corporate entrepreneurship? More nuanced and focussed investigations are, however, emerging. For example, Hayton and Kelly (2006) advocate a competency-based framework for CE, identifying four key competences - innovating, brokering, championing and sponsoring - and the specific human capital characteristics underpinning each. Each competence may be aligned with one or more different roles associated with success of CE, typically residing at different levels in the organisation. Similarly, Hornsby, Kuratko, Shepherd and Bott (2009) identify heterogeneity in the motivation for entrepreneurial action across managerial levels. There remains, however, considerable scope to recognise the complexity and revisit the 'human' in strategic HRM (Wright and McMahon 2011, p. 102) and its role in CE.

\section{Case study context}

Founded in 1847 as Siemens and Halske AG by Werner von Siemens, Siemens offers many products, solutions and services in the fields of General Industry, Healthcare, and Energy Generation and Distribution. At the time of our study, these businesses were run by three sector organisations operating globally. ${ }^{1}$ Within the Industry Sector, the Building Technology division integrates the Siemens offerings in fire safety, security, and building automation by four specific business units: Fire Safety, Security Solutions, Building Automation and Control Products and Systems.

Our focus is on the Fire Safety (FS) business unit. Fire Safety includes the activities in the market of electronic products and solutions used to detect and suppress fires, as well as the product business in two adjacent fields of electronic security. Headquarters of all Building Technology organisations are located in Zug, Switzerland. Historically, the Building Technology division comprises the industry sector of Elektrowatt AG, taken over by Siemens

\footnotetext{
${ }^{1}$ Siemens was restructured in December 2012.
} 
at the end of 1997, with some similar but much smaller activities of Siemens added. Within Elektrowatt, Cerberus AG represented the business in fire safety and security products and solutions. Cerberus AG emerged as a spin-off from ETH (Switzerland) in 1941, industrialising the break-through invention of the ionisation detection principle - the first mechanism identified to detect fire aerosols electrically (Meili 1990). By the mid 1990s, this market had become a multibillion dollar business worldwide with additional products for extinguishing fires automatically, and Cerberus AG gained the world market leader position in this field. Key for market growth was the establishment of strong national and international regulations, declaring such equipment mandatory in most types of publicly accessible buildings.

At the time of our study, Fire Safety, like Siemens in general, was experiencing top management turnover, stagnation and decreased profitability, and had lost its market leadership position. In this climate of crisis, the first author, who had been employed within the Siemens business unit Fire Safety since 1988, was appointed integration manager for the acquired Shinwha Electronics in 2008. This case study of Siemens is thus 'revelatory' (Eisenhardt and Graebner 2007; Yin 2009), with the unique access revealing important insights about the linkages between HRM and corporate entrepreneurship within a large multinational enterprise.

\section{Research design and methods}

\section{Research design}

Our interest in Siemens AG is not because it is a multinational enterprise (MNE) per se, but because it is a special type of multi-establishment firm (Scott 1986, cited in Beugelsdijk and Mudambi 2013). The differentiated network of the MNE (Hedlund 1994) - with subsidiaries often facing diverse geographic, economic, political and cultural contexts (Ghemawat 2011) and roles (Alfoldi, Clegg and McGaughey 2012) - enables us to explore CE across (internally and externally) heterogeneous units but under common ownership and control. To address our research question, we use an embedded case study design in which we explore the 
entrepreneurial behaviour of three local entities within the Siemens AG business unit Fire Safety. A maximum variation approach (Patton 2005) with 'polar' cases (Eisenhardt and Graebner 2007) was used in selecting the three embedded case studies.

The first embedded case study was of Shinwha Siemens, formed by the takeover of Shinwha Ltd (Korea) by Siemens Fire Safety Unit on 1 May 2008. Despite entering the South Korean market in the late 1990s, Fire Safety had only achieved a 0.6\% market share by 2005. Hence it was decided to grow via acquisition. Shinwha was the second largest player in the South Korean market, with a $13 \%$ market share and considered very entrepreneurial. The first author was appointed integration manager for the acquired Shinwha Electronics in 2008, and thus observed events unfold real-time. Turnover and profit of the new Fire Safety Korea entity did not develop as expected by Siemens management. A drastic drop in new order intake led to a dramatic decrease of turnover and negative profits by the end of business year 2010. In the initial pilot study, significant differences in the entrepreneurial orientation and behaviour of the relevant Siemens and Shinwha Ltd management representatives were revealed. Hence, the Siemens Shinwha case was chosen to contrast the 'way of corporate entrepreneurship' at Siemens to the entrepreneurial way within the formerly independent Shinwha Ltd.

The second case study was an example of an entrepreneurial initiative taking place entirely within Siemens. Since 2007, over 200 SMART (Simple, Maintenance-friendly, Affordable, Reliable, Timely) projects have started, aimed at the launch of new businesses in lower end markets as well as Asian-specific product adaptations and additions (depending on local languages and standards). However, the top management was satisfied with neither the speed of project implementation nor the limited scope of many projects, primarily focussing on product innovation aspects and local $\mathrm{R} \& \mathrm{D}$ and manufacturing optimisations. Therefore, Siemens CEO Peter Löscher presented to the top 300 Siemens managers at the yearly Siemens Business Conference in Berlin in October 2009 an additional SMART initiative explicitly aimed at 'fostering local entrepreneurship'. The initiative was also a response to concerns 
about having $70 \%$ of all Siemens headquarters functions still located in Germany, while trying to run a truly global business. Peter Löscher asked the sector heads for a selection of twenty SMART projects to be expanded towards the establishment of a new headquarters function, responsible for the global business and located in Asia. As of 2011, these SMART projects represented the only identifiable actions declared as entrepreneurial endeavours within Siemens and overtly sponsored by top management. The SMART project selected as the second case study started in 2007 in a China subsidiary, and aimed at entering the low end markets of highly priced competitive fire detectors and fire panels not previously addressed by Fire Safety. The case represents a successfully launched new business based on product innovation, the setup of a new organisational unit, and entering new markets world-wide.

The third case study - the 'SP new setup' - is a significantly entrepreneurial endeavour of splitting off the security products business ('SP') of Fire Safety, which was built on the previous acquisition of Bewator Ltd (Sweden) in 2005 and iMetrex Ltd. (in India and Ireland) in 2007. The decision to split off was justified by the Fire Safety management by the doubtful prospect of this business ever attaining profitability within Siemens despite various internal streamlining and optimisation actions. Since an attempt by the end of 2008 to sell the business directly to competitors also failed, the SP new setup project was started in 2009 for the restructuring and carve-out of the business into an independently run company, with the intention that it be sold to a new shareholder. The SP new setup thus represents an unsuccessful business endeavour when looking backwards, and thus adds perspectives on limitations to entrepreneurial activity in the organisational context of Siemens AG. It also represents an alternative model, with the carve-out shedding many of the constraints imposed by being embedded in the Siemens context. 


\section{Data collection and analysis}

Data collection was undertaken from September 2007 to October 2010 in Shinwha Siemens (including a pilot study), and from January 2008 to October 2010 in the other two entities. While the role of the first author in Shinwha Siemens as integration manager allowed the collection of naturally occurring data through participant observation, semi-structured interviews and corporate documents were also collected, and were the main sources of data in the SP new setup and SMART project case studies. Following a monolingual approach (Welch and Piekkari 2006), all interviews were conducted in English, with non-native speakers whose command of English was at a high level (given that it is Siemens' corporate language). ${ }^{2}$ All interviews were audio recorded and transcribed in full. Interviewees included 19 top and middle managers from Europe and Asia, representing general management (e.g. CEO), key business process areas (e.g. R\&D, sales) and HRM personnel across the three case studies. As shown in Table 1, they are drawn from both relevant headquarters and local entities.

\section{[Insert Table 1 about here]}

Interview questions were informed by the prior literature review and sought to elicit the extent to which CE existed within each specific case study and across Siemens more broadly, and the factors that facilitated or impeded its emergence and success. Questions did not focus on the perceived relationship between CE and HRM, except when discussing CE with the HRM managers. We thereby overcame the potential for respondents construing HRM activities

\footnotetext{
${ }^{2}$ The monolingual approach may have limited the possibilities of non-native speakers for delineating details and providing authentic and 'rich' responses exhibiting 'subtle nuances', thus potentially just 'repeating company policy and falling back on jargon' (Welch and Piekkari 2006, p. 428). However, all interviewees were fluent English speakers (as given by English as the corporate' language). For the interview questions, an 'international' English devoid of dialect, idioms and colloquialisms was used 'to reduce the impact of interviews that are "linguistically dysfunctional"' (Welch and Piekkari 2006, p. 429). Furthermore, distortion and inaccuracies of answers caused by language translations could be avoided.
} 
simply in terms of only a 'functional unit'. NVivo software was used to support the analysis. A first cycle of data reduction by thematic coding drew on the extant literature and interview protocol, but also allowed unanticipated meanings to emerge.

Following the thematic coding, data displays and detailed descriptions of the cases and findings were generated (see Miles and Huberman 1994). The data displays and analysis aimed at capturing and describing the central themes and relationships that cut across heterogeneous units in the MNE, as well as explaining differences. For example, in relation to factors affecting the dual needs for exploration and exploitation, we generated a table that recorded perspectives of each interviewee in relation to these dual needs, for each of the three embedded cases and in relation to Siemens AG as a whole. Within each of these four locales, we distinguished between perceptions at different levels of the organisation - that is, senior executives such as $\mathrm{CEO} / \mathrm{CFO} / \mathrm{PL}$ and middle management in headquarters or a subsidiary cross-referencing perceptions by specific (anonymised) individuals. In a subsequent table, we provided a count of occurrence for each of the themes identified and clustered individuals within each theme, while retaining the distinctions between respondents in terms of locale and position in the organisational hierarchy. Hence, our data displays generated from the analysis sought to retain both the richness of the respondents' words as well as summary patterns, while allowing comparisons across organisational units and levels.

These interim findings led to further cycles of (mainly secondary) data gathering and subsequent analysis and, in particular, efforts to derive causal networks (Miles and Huberman 1994) that showed the relationships between organisational antecedents and individual behaviour. These data displays (e.g. concept and thematic tables, causal networks) helped to reduce the 'extended text' of the collected data and to deduce the key points of the analysis by building clusters, identifying relationships and making contrasts and comparisons within each case study and subsequently between case studies. Our methodological approach may be best 
described as abductive (Alfoldi et al 2012, Dew 2007) in that we started with theory, but engaged in a constant iteration between theory and data over the life of the research project.

Our procedures were consistent with those recommended for establishing data 'trustworthiness' (Guba and Lincoln 1994): the first author had 'prolonged engagement' with the research site during the real-time data collection and afterwards; data collection and analysis were concurrent; sources of data were 'triangulated' (Yin 2009); raw data is crossreferenced to provide an 'audit trail' (Morse 1994); and 'member checks' whereby the emerging framework and interpretations were presented to senior executives and broader networks provided useful verification or challenges to interpretations, and sometimes led to additional data that further elaborated the findings.

\section{Findings}

As a way to structure our findings, we adapt Kuratko, Hornsby and Goldsby's (2004) model that identifies individual and organisational elements influencing corporate entrepreneurship (see Figure 1). The model suggests a relationship between implementation outcomes and subsequent behaviour. As Kuratko and colleagues (2004, p. 78) note: ‘An organisation's sustained effort in corporate entrepreneurship is contingent upon individual members continuing to undertake innovative activities and upon positive perceptions of the activity by the organisation's executive management, which will, in turn, support the further allocation of necessary organisational antecedents.'

Our focus in Figure 1 is on the organisational antecedents to individual behaviours for $\mathrm{CE}$, specifically in relation to HRM activities. In contrast to the positive feedback loops discussed by Kuratko and colleagues (2004), in our study the particular configuration of organisational antecedents and their effect on individual entrepreneurial behaviours led to undesirable outcomes for CE - namely, the loss of market leadership and the failure of the business carve-out. Furthermore, we found that the pattern of antecedents and behaviours 
discerned led to sustained inertia in a reportedly low level of CE, as depicted in the feedback loops in Figure 1. This included a perceived a lack of recognition and rewards for entrepreneurial behaviour, weakening motivation to engage in CE. Further, a focus on internal processes rather than external stakeholders and opportunity exploration reinforced a perceived existing tendency towards internally-driven and only incremental technological innovations.

\section{[Insert Figure 1 about here]}

Below we describe our main findings. We have chosen to structure our findings in a manner that, as much as possible, captures how our research participants experience the HRM activities relevant to CE in the Fire Safety Unit. While at time this leads us to discuss formal HRM programmes referred to by the participants (e.g. Siemens Leadership Framework) as organisational antecedents to entrepreneurial behaviour, at other times the antecedents identified by participants (e.g. process-driven organisation) were not immediately obvious as related to human resource management and yet, as we will discuss later, are compellingly so.

\section{Process-driven organisation}

Siemens is widely perceived to be a process-driven company. Business process management encompasses all activities of identification, definition, analysis, design, execution, monitoring, measurement and continuous improvement of business processes. Within Siemens AG, it involves defining performance goals for processes 'top-down'. Process standards and a common process framework are seen as a fundamental basis for a systematic design and optimisation of results, processes, and resources (Rohloff 2011). The Siemens Process Framework consists of a 'reference process house' and common methods for process management across Siemens AG, known as 'reference process definitions'. These process definitions are fundamental for process standardisation and are intended to provide a stable basis for process management. There are five key process areas within the Siemens reference process house: Customer Relationship Management, Supply Chain Management, Product 
Lifecycle Management, overarching Management Processes, and additional Support Processes. The implementation of the process definitions down to concrete and detailed activities and document templates is division-specific. As of 2011, only a comprehensive process for Product Lifecycle Management and a rather weak Supply Chain Management process had been defined and rolled out at the Building Technologies division.

The process orientation of Siemens AG is in part forced by the compliance to various industrial standards required by law or customer demand (e.g. ISO 9000:2000, ISO 14001) and an industry code of practice that expects proof of minimal levels of process maturity. The first stages of process maturity aim typically at people independence - that is, the way tasks are carried out must not depend on which actual employees are involved:

...once the processes are clear, and you are independent from people, you can replace people and top managers, or top project leads more easily, because you are backed up by processes. [CEO BT FS, 21.7.2010]

However, when suggesting to the interviewees that key elements of entrepreneurial activity - especially the aspects of opportunity recognition and evaluation - be added to the process definitions, surprisingly negative feedback emerged:

[...] hopefully I never will see something like this! Because when we would start to describe how to be an entrepreneur and put it into a process, then... this would be for me the old Siemens... where you have 'Rundschreiben' [management circulars], and everybody... everything is explained... I mean, if we do not recruit these kinds of people with this [entrepreneurial] mindset, then we have a problem. So please: never ever describe a process: what is an entrepreneur! [Global Head of FS SYS, 29.7.2010]

A majority of interviewees shared the same perception: entrepreneurship is a 'personal art' and, hence, translating key activities into the company process definitions is 'impossible'. Opportunity exploration, in the sense of identifying new businesses or new business approaches, was reported as almost non-existent in currently defined process activities. At first glance, this seems consistent with Medcof and Song's (2013) suggestion that less formalised HRM processes are necessary in exploration, compared to exploitation. However, all respondents complained about current firm renewal activities being limited to internally- 
driven, technical innovations only, and a lack of an external focus. This was particularly evident in the Shinwha case. There was consensus in 2011 in the Fire Safety management that Shinwha's dramatic drop in sales was primarily due to the neglect of personal customer relationships by Shinwha sales forces. It turned out that there was neither a detailed identification of key customer relationship owners, nor a subsequent transfer of these relations from sales managers - who left following the acquisition - to internal successors. Indeed, Customer Relationship Management process definitions were not implemented at all in Fire Safety at the time of our study. Notably, the Siemens assessment questionnaire used to judge the Shinwha integration process contained detailed questions concerning proceedings in internal processes, tools, IT infrastructure, and organisational set up - but there were no questions about the customer relations of top and middle management at Siemens Shinwha, key account management, or related market activities. Nor did a customer focus emerge in the official audit of the firm integration - despite its reported importance:

...our local business is based on relationship. [...] long term relationship [is] very, very important for the local business in Korea. [CFO BT KR, 9.8.2010]

... on competences I think we have a massive, massive gap, between what we need, going forward as an organisation, and what we have today. [W] e are trying to see the world based on the solutions which we are comfortable delivering - not so much... we don't see the customer [...] from his point of view, what is it that he needs, end to end. [Chief Marketing Officer BT, 4.10.2010].

Throughout all cases, customer relationships are reported as highly person-specific and requiring many years of build-up to become effective in selling products and solutions. The absence of specific processes or HRM activities designed to capture the key knowledge and opportunities that can be derived through customer networks and, indeed, transfer the network relationships themselves, led to a loss of deep knowledge of the subsidiary's internal and external context necessary for ongoing opportunity identification (Chadwick and Dabu 2009).

Overall, the views expressed regarding the established Siemens organisation were very homogenous across all three cases. Opportunity identification was reported as almost nonexistant existing in currently defined processes. Related, the lack of new opportunity 
identification through exploration, as opposed to exploitation of opportunities, was seen less in the amount of resources than in the capabilities of the employees - a view which was most popular among headquarters executives. Recognising that different capabilities and priorities may be required, a majority of interviewees preferred a separation of people doing exploration and exploitation:

[...] have dedicated resources, at least for a start-up, if you have a new business idea, put people together... in best: a very diverse group, with different business backgrounds, different histories, different knowledge; and let them work out the strategy, the concept, in a kind of project... or [a] competence centre approach. And once you have achieved the first level of maturity, you should bring it back into the normal organisation [...] [CEO BT FS, 21.7.2010].

At the time the field research took place, a separate team existed only for technology innovation at Fire Safety, and the investigation of potential new endeavours was set up as an ad-hoc project not following defined processes.

Significant variation was identified in the comprehensiveness and maturity of processes throughout the three investigated cases. Shinwha Ltd, as an entrepreneurial medium-sized firm, used simple process models covering key aspects of product innovation and supply chain management. With its integration into Siemens, it was decided to introduce only a subset of established Siemens processes in order not to overstrain the capabilities of the organisation and employees. Within the SP new setup organisation, a drastic reduction of the complexity of the established Siemens processes was taking place at the time of the field research. The SMART project in contrast must use the given Siemens processes, although it can use simpler versions. At the same time, however, requests were launched from the SMART project team members for a significant reduction of process complexity.

\section{Selection criteria: Siemens leadership framework}

Two respondents advocated the reduction of people dependence in CE by good processes, allowing the short term exchange of employees without impairing the firm's performance. This perception - which might well be applicable in routine jobs on the business exploitation side - 
was strongly rejected by most. If processes cannot be devised to make CE people-independent, selection criteria take on elevated importance:

...no matter how you change this backwards and forwards, people are the key factor $[\ldots]$, because there is no machine that can invent something new. [...] Even though there might be a process to do so, without the right people living those processes, you have no chance for future success. [Management Development at Siemens Corporate Office, 9.11.2010]

The Siemens Leadership Framework defines the required set of employee capabilities for particular functions and levels within the organisation, as well as current levels of individual capabilities. It outlines, primarily, nine specific capabilities used for job reference profile definitions and related measurements - or judgments - of candidates and employees: Business Results Orientation, Strategic-Innovative Orientation, Customer Orientation, Change Management, Collaboration and Influencing, Intercultural Sensitivity, Leadership, Team Development, and Value Orientation. In March 2010 the framework was updated - cutting capability dimensions from eighteen to nine, and introducing seven levels of expertise per capability in detailed textual descriptions. However, at the time of our data collection, terms such as 'entrepreneurship', 'intrapreneurship', 'venturing' or 'uncertainty' could not be found in the extensive description, and 'risk' appears primarily in the context of controlling risk.

Based on the Siemens Leadership Framework, reference profiles of typical jobs were defined and introduced. The seven levels of capability maturity were unfortunately primarily linked with the hierarchical position of the job within the company. Thus, a divisional CEO position ends up with capability levels of four to five (on a 7 point scale), whereas senior consultants (as an example of low ranked employees) only reach levels of two for all capabilities (and leadership and team development capabilities are even declared 'nonapplicable'). The first capability ranking of employees was completed by the end of 2010 with these target definitions. It was suggested by top management that it be treated as the average ranking over all employees doing the same job definition. However, massive protests ensued, with employees seeing these 'norms' as having little to do with their real capabilities, but more 
so with predefined results. The reference profiles were thus withdrawn and completely deleted from the Siemens intranet. Any judgments were declared voluntary by the employee for 2010 and 2011. Overall, though, there was a perception that entrepreneurial capabilities were lacking due to an inward-looking tendency and inappropriate selection criteria.

\section{'Top talent' career concept}

The top talent programme is part of the Siemens people excellence initiative. Specific guidelines and processes are defined to identify and develop selected individuals towards executive positions. Those in the 'top talent' pool represent human capital in Siemens that is both valuable and unique. 'Value' refers to the potential of the human capital at hand to contribute to its organisation's core competence and enhance its competitive advantage, whereas 'uniqueness' refers to the extent to which the organisation's human capital would be difficult to replace (Lepak and Snell 2002). Where the human capital is both unique and valuable, one might expect a clear preference for intra-organisational career mobility and formalised career management practices (De Vos and Dries 2013). This is the case with the Siemens 'top talent'. A key selection criterion is the potential of a candidate to climb up the Siemens career ladder by at least two functional levels within five to seven years. Specific coaches outside the candidate's immediate organisation are provided to top talents, typically serving in the positions targeted (i.e. two levels higher than the coached person). In addition, specific seminar programmes are run for junior top talents (typically limited to a participant age of 40), allowing them to develop direct contacts with top executives, with educational seminars organised by HRM functions. Top talents must sign their consent to be ready to move to any work place on the globe to be allowed participation in the programme. Furthermore, a top talent is required to have served in at least two completely different areas of the business covered by Siemens before being promoted to an executive function. It is usual, therefore, to 
send top talents as time-limited delegates (typically two and not more than three years) into key functions abroad.

In terms of fostering CE, Chadwick and Dabu (2009, p. 266) argue that 'career development programmes that allow key employees to rotate through different functional assignments within the firm may also foment ideas that cut across the more parochial concerns of a firm's hierarchical divisions.' The nature of the 'top talent' programme at Siemens was, however, seen by many respondents to undermine CE at Siemens, leading to a risk aversion and a short-term orientation, as shown in Figure 1. Within Siemens Building Technologies and Fire Safety, CEOs on the level of business units or country organisations typically stay for two to three years and then move on. Indeed, Siemens 'top talents' must show development to the next higher levels of Siemens to maintain their status. In contrast, the CEOs of the acquired and entrepreneurial Shinwha Electronics and iMetrex served, or rather acted, as independent entrepreneurs for ten years and more.

The 2-3 year stays in a specific executive position proved to be highly controversial within Siemens, with virtually all interviewees judging these service periods to be too short. For example, clans of entrepreneurially experienced employees and domain experts facilitate opportunity identification (Mahnke et al 2007), but depend on continuing communication and close relations among their members (Alvarez and Barney 2005). The Siemens career model of changing positions within two to three years undermines the persistence of clans over time. Similarly it was perceived to undermine the development of domain specific business knowledge. This domain knowledge relates not only to technologies, but also industry characteristics and long term relationships with, for example, customers:

Because domain knowledge in Building Technologies doesn't get built in months, it takes years... [I'm] not so convinced about the model of... rotation... it is maybe fine from an individual's career point of view, but from a business point of view, not to have domain experts serving functions over time, and growing within a domain is a big loss for the organisation. [...]Building Technologies needs to hire more people from competition, and not so much from internal... found within Siemens... [...] let's not take away the fact, that the more knowledgeable you 
are... you will actually be able to make more entrepreneurial decisions. [Chief Marketing Officer BT, 4.10.2010]

Nevertheless, only two respondents claimed an undoubted existence of a direct relation between length of service and delivered business results. Periods of service of 10 years and more were seen as negative and leading to a standstill regarding new ventures, and it was also claimed that the variation in personal inclinations towards entrepreneurial endeavours and rewards for entrepreneurial behaviour would be more of a determinant than the years of service. The short stays were, however, tightly coupled with how performance is typically measured within the Building Technologies Division, with an emphasis on yearly (and quarterly) performance measures for business units, and annually for individuals:

... we focus on the next year performance, short term performance, but... in order to create and find new business, we need a certain investment in a certain period, but without any activity... results, then I think, the working level, they don't like to invest their time for new businesses, because that... they measure their current performance - that is the conflict. [Head of R\&D and Manufacturing at FS Korea, 3.11.2010]

The short-term orientation was exacerbated by a career-making tendency seen as endemic among 'top talents' that reinforced the existing performance mechanisms. This is not surprising: to join the top talent' programme is a declaration of intent to climb the corporate hierarchy. Such career-making in the context of Siemens was not, however, seen as consistent with entrepreneurial endeavours, where the impact of decisions and actions often only come to fruition after an extended time period (Lumpkin, Brigham and Moss 2010):

[I]f you have only career making people, $[\ldots]$ they are the wrong ones... [...] trying to be an entrepreneur is stopped by those guys at any time. [...] [Y]ou must really shape the people into a different culture to really have this more entrepreneurial thing [...] and you don't need to hire people who want to make careers [Head of Product Line within SP new setup, 19.8.2010].

Most people are thinking about going up the ladder, rather than creating something as a real legacy for the business that they are managing right now. [...] I don't think the succession planning is very effective within Siemens, and I don't think that rewards entrepreneurship as well. ...[T]here is not enough emphasis placed on creating and being entrepreneurial. This structure is backed by KPIs. [CEO of SP new setup, 1.10.2010] 
Overall, in the context of Siemens entities (including the SP new setup), respondents sought longer-term stays in specific positions to overcome the personal career-making orientation that was perceived to dominate, gaps in the business domain knowledge and few incentives to go for longer term entrepreneurial endeavours. They also sought more CE competencies to be recognised and embedded into selection processes. No comparable claims emerged within the context of the previously independent Shinwha and iMetrex entities. The significant entrepreneurial activity of the owners of Shinwha and iMetrex - who were also the long term executives - was reflected by the high growth rates of their business and confirmed by interviewees. In the Shinwha acquisition, due diligence investigations highlighted that key staff in $\mathrm{R} \& \mathrm{D}$, manufacturing and sales also served longer terms (i.e. five or more years).

\section{Organisational Milieu}

HRM activities are, of course, embedded within a broader organisational context. The shortterm orientation towards staffing assignments and performance appraisals identified above was couched in a broader planning context within Siemens:

I really think that long-term orientation is one of the key aspects that we have lost over the years... If you define what long term is: [...] five years and above, and when it comes to that kind of planning, it is not particularly visible, I know that we do it, but it is not visible... [Management Development at Siemens Corporate Office, 9.11.2010]

Consistent with the extant literature, risk-taking behaviours, forgiveness for entrepreneurial failure and empowerment of (potential) entrepreneurs were all seen as key to CE by respondents, but were perceived at all levels to be somewhat lacking in the organisational culture. Several respondents perceived Siemens to be a 'zero risk culture':

[...] if you say: I have taken a risk - it's a bad thing in Siemens! [...] So if you are the leader in a business unit, at the moment the culture is: not to show that you are taking a risk! ... [T] he current recognition is for zero risk! Nobody is motivated to give you a new idea, because there is always a risk [Regional Manager for Korea in FS HQ, 3.9.2010] 
This was especially seen as linked to concerns about not endangering one's own career by

endeavours which may fail, based on a perceived lack of forgiveness for such failures and little expectation of receiving significant recognition for success:

$[\ldots][W]$ lack the culture of trial and error, and we don't want to get punished for doing something wrong, and... [...] rather following the rules than trying something new; and entrepreneurial: try something, take the risk. [Integration Manager iMetrex, 15.9.2010]

These attributes of Siemens' organisational culture were reinforced by HRM practices.

The top talent career concept described above, for example, favoured home country executives - that is, German nationals. Perceived low levels of risk taking in the three case studies were directly connected by interviewees to the still dominant role of German managers:

$[\ldots]$ you would find more risk takers in other cultures than in Germany... The German culture per definition is not particularly risk taking [Management Development at Siemens Corporate Office, 9.11.2010].

I think, in terms of risk taking, German people are typically quite risk-aware, so... also we at Siemens have certainly a tendency to more focus on the short term things, on the existing things, other people are much more open to take risks, and they are also willing to invest at them... [Global Project Lead SMART Initiative, 21.10.2010]

Efforts made to strengthen diversity at Siemens AG in recent years were not seen by those interviewed as effective, and most key executive positions at Building Technologies are still held by Germans. As a contrast, middle management in the regions - typically representing local nationalities - was seen as having entrepreneurial drive, but were being hindered in pursuing entrepreneurial endeavours:

[...] if given the opportunity, they were able to exercise some entrepreneurial spirit. It means us taking a risk, it means us being willing to take risks in certain regions, and accepting that entrepreneurial activity generally means that one in however many ideas really flies, and a number of them fail, and not persecuting people for failure. [...] Because at the moment we have a tendency to say: I told you so, rather than say: at least we tried [...] [A]t the moment, there is nothing there that gives the people the opportunity to invest in an idea... [Regional Manager for Korea in FS HQ, 3.9.2010]

Notably, for the SP new setup it was decided to appoint a new CEO with a given track record of being an independent entrepreneur. This represents a quite interesting finding: the repeated 
yearly losses in the business, and the aim of achieving a turnaround and subsequent exit led to the appointment of an entrepreneurial character - which was not reported at all as an ingredient considered as important for executive appointments in those entities staying within Siemens.

Decisiveness - in the sense of taking decisions frequently and in a short time frame - was also a strong theme that emerged in the interviews. It implies a tolerance for ambiguity and willingness to take decisions on sometimes largely incomplete information (Cromie and $\mathrm{O}$ Donaghue 1992). While decisiveness is not emphasised in reviews of literature on CE, its role as a central ingredient to CE at Siemens FS was widely shared by respondents. The highly successful former (independent) entrepreneur and main owner of iMetrex, put it quite simply:

First of all there has to be a culture of taking decisions, and taking ownership, this has to be broadened. [...] For me, entrepreneurship - without even thinking would be a bias for decision. [Chief Marketing Officer BT, 4.10.2010]

This view was shared by the CEO of Fire Safety, although he had never acted as an independent entrepreneur before: 'Entrepreneurship is... being successful with the $80 \%$ approach.... meaning: a fast decision is better than no decision.' Many respondents saw a severe lack of such decisiveness within Siemens entities, strongly linked with a risk-averse culture, a perceived absence of forgiveness for failure, and a lack of empowerment:

And if you try to be entrepreneurial, that means: doing decisions based on your own understanding what is right and wrong, you are quite often... you are stopped, and halted by other people, who feel: 'oh this is too fast, I was not involved'... by... whatever, by Bas [business administrators], or by compliance, or by whatever rules... [Head of Product Line within SP new setup, 19.8.2010]

Nobody wants to make a decision, because as soon as he does a decision, and it might be that this decision is wrong, we have the culture that $[\ldots]$ he needs to be punished. [...] Therefore, it is better to ask first, first the top management before I am doing a bigger... decision. Or whenever you need to make a decision, to do this decision in such a way, that the decision maker has at least the possibility to find somebody who can be blamed. [Global Head of FS Human Resources, 20.8.2010]

Similarly, 'collective' decision making - rather than empowering individuals and making them directly accountable - was perceived as a legacy of the Siemens culture:

[W] e are from a cultural history rather used to taking decisions together, so that in the end nobody is responsible. [...] I think that they are very closely linked, the 
decisiveness and the risk-aversion. [Management Development at Siemens Corporate Office, 9.11.2010]

In contrast, decision-making towards entrepreneurial endeavours in the formerly independent Shinwha and iMetrex entities was primarily done by the top management. For the SP new setup, an emerging culture of taking decisions based on the more comprehensive involvement of all stakeholders was reported. This approach was seen to require more time for decisions, but also as leading to more commitment of those involved, thereby creating more sustainable and successful decisions. How to balance the trade-off between decisiveness and generating collective commitment among relevant stakeholders remains a key question for Siemens FS, and many large firms. Consistent with being a process-oriented organisation, most respondents favoured activities to strengthen decisiveness in compliance to defined rules. From a human resource management perspective, it was proposed that higher levels of decisiveness could be achieved by appropriate people selection and a changed attitude in management:

...in the recruiting process: to have more people who really are... willing to make this decision and have the capabilities to do it. And at the end, I mean... this cultural change, we can as well try to influence the line management in order to go more in this direction... with all the limits HR has. [Global Head of FS Human Resources, 20.8.2010]

\section{Empowerment through 'certifications' and competence}

In our study, respondents perceive that the lack of decisiveness and centralised decisionmaking dis-empowered the overseas subsidiary managers, and thus gave them little incentive to share knowledge and entrepreneurial opportunities with either Fire Safety or Global headquarters. The nature of multinational enterprises, being geographically dispersed, made experimentation at the local level perhaps more possible than in more simple organisational structures (Alfoldi et al 2012). Hence, the level of CE within Siemen's may be underestimated:

[...] headquarters are not made aware of all the creativity that goes on in the regions. For fear of analysis, too many questions, hindering... or even stopping them from doing it again. So, some of the... entrepreneurial behaviour is not visible to us here, because the regions don't want it to be. And that's a cultural thing we need to break... [Regional Manager for Korea in FS HQ, 3.9.2010]. 
In the context of granting more comprehensive mandates with more local autonomy for new business venturing, the CEO of Building Technologies presented at the Global Management Conference in May 2010 the idea of turning Building Technologies into a global Systems House (i.e. providing customer specific solutions and turnkey systems typically integrating different Divisions), and having subsidiaries and specialists certified. Such an approach was started in 2007 in Fire Extinguishing by Fire Safety as a pilot project - and perceived as quite successful - to achieve three specific goals: to 'effectively make qualified investments in Building Technologies business growth opportunities', to 'manage existing financial and reputational risks', and to 'secure the needed (solution) experts with the right qualifications'. Certification levels (Blue, Silver, Gold) granted to subsidiaries would be highly dependent on business performance (growth and profit) and process maturity to manage quality and risk. Similarly, employees were to be certified by using the three levels: professional, advanced and expert. That is, there appeared a shift to a more competence-based approach to HRM. By the end of 2010, a certification manager at divisional level had been appointed to implement this initiative. This certification approach received very positive feedback:

[This] initiative sends that message: Do your internal stuff well, and I give you more freedom on your external. [...] And I think that this is a great platform for launching... or, not launching, but fostering entrepreneurial behaviour. And I think it will attract different people to our business, to lead branches. I think they will aspire to get 'Gold' status, so that they get the freedom to do what they believe is right to run their business. [Regional Manager for Korea in FS HQ, 3.9.2010].

The development of subsidiary and employee certification also addressed the concern by a number of respondents that processes, while seen as appropriate on the exploitation side of CE, were an impediment on the exploration side:

...entrepreneurial behaviour which is [...] taking opportunities in the market, seeing them before other people do, and exploiting those opportunities with some sort of solution or offering, [...] quite frankly, processes are a distraction, are an internal activity. And they are very important about getting consistent delivery in what we do, but should the entrepreneur be tasked with running them? [Regional Manager for Korea in FS HQ, 3.9.2010] 
That is, because certification granted more comprehensive business mandates based on proven profit delivery and process maturity on the operational side of the business, there was less need to apply further tight controls to the business development or opportunity exploration side of the business. The award of certification levels, however, had a less obvious but important effect: it signalled recognition, with the resultant greater autonomy seen as a reward. Recognition signals the importance of entrepreneurial values to the organisation and creates legitimacy for such endeavours (Hayton 2005), and non-financial rewards such as recognition by praise and granting certificates have been found important to support an entrepreneurial culture in previous studies (Block and Ornati 1987; Brazeal 1993; Chandler, Keller and Lyon 2000; Hornsby et al 1999; Sykes 1992), as in the present study. If successful, these competence-based certifications of subsidiaries and individuals may help foster positive feedback loops in Figure 1.

\section{Discussion}

Strategic HRM research has previously been criticised for focussing too narrowly on the perceptions of formal HRM practices held by HRM departments' personnel and top management (Bowen and Ostroff 2004) and single-respondent, cross-sectional survey designs (Wright et al. 2001), rather than on how workers and subsidiary or divisional managers actually experience them. This critique can also be extended to recent studies linking corporate entrepreneurship and HRM, such as those based on surveys of top executives (e.g. CEO, CFO) or personnel directors (e.g. Kaya 2006; Tang et al, 2015). A consequence of this dominant methodological approach is that research captures neither the formal managerial entrepreneurship that is directed by decision makers through HRM systems, nor the more spontaneous informal managerial entrepreneurship fuelled by workers' discretionary efforts. Building on Chadwick and Dabu's (2009) arguments, our study explores perspectives of managers and employees at multiple levels within the organisation, and across local entities. 
We identify some effective managerial entrepreneurship (e.g. the certification initiative) but, more so, how inertia in low levels of CE is sustained, contrary to intent of the formal HRM systems and practices. Below, we discuss the managerial entrepreneurship found in our case study - with a focus on HRM - and elaborate two areas of contribution to theory.

\section{Managerial Entrepreneurship at Siemens Fire Safety}

Table 2 summarises our findings in relation to Chadwick and Dabu's (2009) roles that HRM activities play in supporting (or impeding) CE - namely, acquisition, training, motivation and coordination/ deployment. Notably, not all these HRM activities are undertaken by formal HRM departments. In addition to identifying specific HRM activities in Siemens Fire Safety and their positive or negative impact on $\mathrm{CE}$, we highlight those areas of support for and extensions to activities identified by Chadwick and Dabu (2009).

\section{[Insert Table 2 About Here]}

Chadwick and Dabu (2009, p. 266) argue that coordination and deployment are 'the most important human resource activities supporting entrepreneurial rents.' There is considerable support in our findings for this claim. For example, clan membership and the new certification process defined for subsidiary entities and experts are positive examples within Siemens Fire Safety of mechanisms for coordinating and deploying human resources for knowledge generation and exploitation. The clan structure facilitates idiosyncratic, spontaneous recombinations of knowledge, while the certification process provides a structure that defines the parameters within which autonomy can be exercised. Yet to elevate coordination and deployment above the other HRM activities of acquisition, retention, training and motivation overlooks the inevitable interactions between activities, as captured in Table 2. Recruiting and ensuring a stable cadre of 'top talent' expatriates enables the transfer of knowledge throughout the MNE through international assignments (see 'Acquisition' in Table 2). These international assignments are also an important part of management development or training for members of 
the 'top talent' cadre (see 'Training' in Table 2). The short duration in each assignment for a 'top talent' was, however, problematic (see 'Retention' in Table 2). The maximum of three year stays was linked to a key selection criterion being the potential of a candidate to climb up the Siemens career ladder by at least two functional levels within five to seven years. Short stays undermined the development of deep domain knowledge, communication in clans and a longer-term orientation towards performance objectives. Indeed, performance measures over a short time horizon and related limits to discretionary behaviour provided little incentive to generate entrepreneurial rents by building businesses that are sustainable over longer time horizons (see 'Motivation' in Table 2).

While the findings of these case studies confirm many prior studies pointing to the linkages between $\mathrm{HR}$ activities and $\mathrm{CE}$, they also bring to the fore several important aspects that are less evident in prior studies. First, is the importance of firm-specific context. Extensive literature reviews of the links between CE and HR activities (e.g. Hayton 2005) or the search for overarching models that can be generalised or widely applied (e.g. Ireland et al. 2009) inevitably obscure heterogeneity between firms operating even within the same sector. Corporate entrepreneurship is often associated with fast paced environments with shortening product lifecycles. In that context, the relevance of long-term orientation that appeared so important in the present study is perhaps more limited (Eisenhardt 1989). In contrast, in the context of Siemens' Fire Safety business unit, product life cycles are up to fifteen years. Indeed, how one defines 'long term orientation' will, in terms of clock-based time, vary according to industry pace. Similarly, Siemens is a highly process-driven organisation, reliant on clearly defined processes in business operations that are centrally developed and deployed. Siemens' process definitions are significantly more stable over time than formal organisational structures within Siemens.

Strategic HRM activities to foster CE need to take account of, and perhaps leverage, enduring and influential organisational antecedents. At the same time, there is a need to 
recognise the importance of interactions between activities - as integrative frameworks based on extensive reviews attempt - but in a more nuanced, context-specific way (Hayton et al 2013). To this end, we still need richer conceptualisations of some of the foundations on which our integrative frameworks are built. We thus offer two theoretical contributions below by (1) elaborating the links between a process-orientation, exploration and exploitation of opportunities; and (2) refining to our current understanding of human competencies for $\mathrm{CE}$, including the relationship between competencies and a process-orientation.

\section{Process-Orientation, Exploration and Exploitation}

In a process-oriented organisation, clearly defined and prescribed processes are central to the coordination and deployment of human resources through the designation of tasks, roles, role relationships and responsibilities. When contributing to competitive advantage, devising and applying these formal business processes is a strategic activity of human resource management and part of managerial entrepreneurship - albeit not necessarily performed by the formal HRM department. The literature on business process modelling and HRM have, however, developed largely as separate streams of research with seemingly little interaction. Where the two co-exist, HRM tends to be cast in a purely operational role, providing performance measurement techniques and job descriptions to help optimisation, with human resources cast as an 'input' to processes (e.g. Glykas 2011). Other studies stress the importance of teamwork in process-orientated organisations (e.g. Kohlbacher and Gruenwald 2011; Kohlbacher and Rijers 2013) but what this means in terms of human resource activities or management is rarely unpacked. Our study within Siemens AG shows that a more critical and nuanced discussion of the relationship between HRM activities and process-driven orientations is warranted.

An important consequence for $\mathrm{CE}$ arises when organisational processes are designed and intended to create 'person independence' in the knowledge coordination and deployment activities of HRM. In such instances, the aim is that core processes can be executed largely 
irrespective of the specific persons - or human capital - performing the process. Indeed, the ability to achieve 'person independence' (as sought at Siemens) may be assessed positively as evidence of 'process maturity' (Rohlof 2011) and, related, an indicator of the value of the prescribed business process as a potential source of competitive advantage (Kohlbacher 2010). At the same time, however, person independence through process maturity negates what Wright and colleagues (2011) identify as a distinguishing characteristic of human resources, namely 'free will'. While this 'free will' component of employees makes the use of human capital as a source of competitive advantage problematic (Wright et al 2011) in the sense that employees can choose how much to contribute to organisational goals (Wright et al 2001), free will also underpins the spontaneous informal managerial entrepreneurship essential for CE. Even unintentional supplanting of free will by slavish use of process definitions designed to engender operational efficiency, quality or risk minimisation may place at risk entrepreneurial outcomes.

A complexity in the use of business processes includes knowing when, or when not, to devise and deploy business processes that have an impact on CE. On the one hand, the research participants in Siemens saw significant merit in the development of processes for the exploitation of entrepreneurial opportunities. On the other, there was strong and largely intuitive resistance to the suggestion of developing processes for exploration activities. This is not inconsistent with extant theory. Both exploration and exploitation of entrepreneurial activities involve some degree of learning, although the nature and extent of that learning differs. As March (1991) states, 'The essence of exploitation is the refinement and extension of existing competencies, technologies, and paradigms. ... The essence of exploration is experimentation with new alternatives' (1991: 85). That is, exploration and exploitation differ in the type and amount of learning needed (Gupta, Smith and Shalley 2006). Explorative learning is characterised by higher levels of uncertainty, in the sense that what is found is new, unknown and unpredictable. In requiring experimentation, explorative learning draws on the 
'free will' and individual discretion that Wright and colleagues (2011) observe distinguishes human resources from other types of resource. This makes devising business processes for exploration more problematic; by definition, they will constrain the emergence of the 'new' (Benner and Tushman 2003), experimentation and individual discretion. In contrast, exploitation of entrepreneurial opportunities often succeeds over the long run by reducing variability and maximising efficiency through tight coordination. In shaping human resource activity, formal business processes restrict discretionary behaviour and thereby reducing variability and enhancing efficiency.

Proposition 1a: Formal business processes are better suited to foster effective coordination and deployment of knowledge for the exploitation of entrepreneurial opportunities where consistency and efficiency is paramount, than for the exploration of entrepreneurial opportunities where the 'free will' inherent in human capital and related discretionary behaviour comes to the fore.

That said, our data also suggests that while process definitions intended to support the exploitation of opportunities may not directly guide explorative behaviour through the assignment of roles and tasks, they can in fact constitute mechanisms for knowledge exchange and help create a context conducive to the exploration of entrepreneurial opportunities. For example, the absence of process definitions in Customer Relationship Management (CRM) was perceived as a missing ingredient in the exploitation of previously identified opportunities and credited as a cause of declining sales in Siemens Fire Safety. However, the application of formal CRM processes also creates a context and mechanisms for social interactions between employees and customers through which novel, external knowledge (e.g. of emerging customer needs) can be more readily identified. Hence, formal CRM processes can fosters informal managerial entrepreneurship for exploration of entrepreneurial opportunities.

Proposition 1b: Organisational process definitions for the exploitation of entrepreneurial opportunities potentially create a context and mechanisms whereby exploration activities can be more readily undertaken, even when this is not the primary 
intent. That is, HR activities intended to facilitate exploitation of entrepreneurial opportunities may have positive 'spillovers' for the exploration of opportunities.

\section{Competencies for $\mathrm{CE}$}

The potentially differential effect of process definitions on exploration (i.e. a potentially negative effect) and exploitation (i.e. a positive effect) can in part ameliorated through a competence-based approach to HR acquisition and retention. Individual competencies are aggregates of the knowledge required to achieve a desired outcome, the skills to use that knowledge, and the personal characteristics needed to motivate the use of this knowledge and skills (Hayton and Kelly 2006). For example, Hayton and Kelly (2006, p. 415) describe an 'innovative competence' in $\mathrm{CE}$ that is a function of domain-specific knowledge, cognitive ability and creativity. These authors argue that a competency-based approach is superior to more traditional job-analytic approaches for a variety of reasons. Only the broad behavioural requirements for $\mathrm{CE}$ are knowable in advance; it is difficult to identify who in an organisation will identify new opportunities; and entrepreneurial activities are likely to occur erratically and infrequently and may thus be missed by traditional methods of job analysis. In effect, their argument points to the uncertainty inherent in explorative learning.

Yet, as discussed above, this genuine uncertainty (as opposed to calculable risk) is not as prevalent in the exploitation of entrepreneurial opportunities, where the emphasis is on learning based on prior activities rather than experimentation and novel, individual discretion. As such, our conjecture is that process definitions may, in part, be substituted for individual competencies within the exploitation activities of entrepreneurial endeavours. This may be especially appropriate in a process-driven organisation such as Siemens AG, where process definitions are an accepted part of organisational life and hence more readily adopted by organisational members. We thus go beyond Hayton and Kelly's competencies for CE to 
recognise that process definitions and competency based approaches may have different utilities according to the aspect of $\mathrm{CE}$ (exploration or exploitation) under consideration.

Proposition 2a: While a competence-based approach to the acquisition and retention of human resources is important for corporate entrepreneurship in general, it takes on elevated importance when seeking to coordinate and deploy knowledge for the exploration of entrepreneurial opportunities. In contrast, human competences may be more readily substituted by formal business processes in the exploitation activities.

A strong theme that emerged from our data collection and analysis was the importance of 'decisiveness' as a characteristic of executives who may, or may not, support CE. The need for decisiveness - in the sense of taking decisions frequently and in a short time frame features in studies of individual entrepreneurs (Hisrich, Langan-Fox and Grant 2007; Miner 1997, 2000). As Floyd and Woolridge (1999) observe, speed, flexibility and decisiveness are central to entrepreneurship. Yet decisiveness does not feature as an important ingredient in the CE literature. Our findings suggest, however, that it is an important (yet unrecognised) characteristic underlying a 'competence in sponsoring CE' identified by Hayton and Kelly (2006). Sponsoring involves helping entrepreneurs gain access to resources they need to pursue opportunities identified, and providing advice and guidance. While a 'champion' identifies and selects projects deserving support, sponsors ensure the necessary resource availability. Hayton and Kelly (2006) argue that executive sponsors bridge the technological innovator and the firm's owner/founders. Perhaps more importantly, sponsors create the context in which the exploitation of an opportunity is possible, and thereby act as the bridge between exploration and exploitation.

The key characteristics underlying a sponsoring competence for CE include deep business and technological knowledge that allows the 'business insight necessary for making risky or even uncertain investments' and 'a willingness to accept risk', as well as 'transformational leadership' and 'tenacity' (Hayton and Kelly 2006, p. 418). Our findings 
suggest, however, that decisiveness is also a central ingredient. Decisiveness does not necessarily imply a greater tolerance for risk and uncertainty. On the contrary, Eisenhardt (1989) found that fast decision-making was associated with more information, rather than less, and more information can serve to either increase or decrease perceptions of calculable risk or genuine uncertainty. That is, risk tolerance is not a conceptual substitute for decisiveness. A willingness to make fast decisions often can also signal confidence on the part of the executive (cf Eisenhardt 1989). Confidence (even over-confidence) may in turn attract the support and commitment of others (Hayward, Forster, Saravathy and Fredrickson 2010). Hence, executive sponsors who are decisive are more likely to attract support and resources for a new venture, even where they do not have direct authority over those resources. Of course, decisiveness may not always result in the pursuit of a new venture, but could also lead to a withdrawal of sponsorship and thereby release resources to pursue alternative opportunities. Either way, a decision made in a timely manner about whether or not to sponsor a new venture is arguably the foundation stone in the bridge between exploration and exploitation. Hence, we posit:

Proposition $2 \boldsymbol{b}$. Decisiveness is conceptually distinct from a tolerance for risk or uncertainty, and an essential characteristic underpinning a competence in sponsoring $\mathrm{CE}$ that acts as a bridge between opportunity exploration and exploitation.

\section{Concluding Remarks}

Tang and colleagues (2015) observe that despite a large volume of research on the links between strategic HRM and firm competitiveness, little attention has been paid to its links with corporate entrepreneurship. Related, Medcof and Song (2014) suggest that perhaps the most fundamental strategic question facing HR today is what alternatives to formalised HR systems exist for entrepreneurial context. Chadwick and Dabu (2009) go some way to addressing this question by suggesting informal, often spontaneous worker behaviours and how CE is shaped by HRM systems and activities is 'fundamental to constructing more complete theoretic models in SHRM research' (p. 269). To generate the necessary insights, scholars of HRM 
have called for more qualitative research that explores the subtle and complex interactions between HRM, organisational antecedents and CE (Chadwick and Dabu 2009, Hayton et al 2013). We respond directly to these concerns and recent calls through a rich, qualitative case study of corporate entrepreneurship within three entities of the Fire Safety Business Unit of Siemens AG, in which we seek to understand how HRM practices serve to overcome, or potentially sustain, inertia in low levels of corporate entrepreneurship.

Our findings complement, challenge and extend prior research and theory on the relationship between strategic HRM and corporate entrepreneurship. In accord with prior studies (e.g. Ireland et al 2009; Kuratko et al, 2004) that suggest a bundle of 'fits' are necessary for CE success, we identify a configuration of inter-dependent factors that mutually reinforce each other and shape CE endeavours. However, rather than leading to success as in prior studies, the configuration that we observed led to sustained inertia in low levels of corporate entrepreneurship - contrary to the intent of the formal HR systems and practices. Further, in contrast to Chadwick and Dabu's (2009) suggestion that knowledge coordination and deployment are the most important HR activities supporting CE, we found the acquisition, training, retention and motivation roles of $\mathrm{HR}$ activities overlapping and interdependent with knowledge coordination and deployment mechanisms, and not merely 'supporting acts'. Our study highlights the potential of scholarship that is richly contextualised and located in specific organisational settings to further our understanding of key variables and interdependencies.

We extend current understanding of the links between CE and strategic HRM through the identification and theorisation of the effect of an organisational process-orientation on CE. Indeed, the identification of the potential impact of a process-orientation on $\mathrm{CE}$ is, in itself, a novel contribution. While comprehensive reviews of the effects of a process orientation on organisational performance point to benefits for quality, customer satisfaction, cost reductions and improved financial performance (e.g. Kohlbacher 2010), its potential effect on CE is overlooked. Similarly, it is not uncommon for studies linking human resource practices and 
CE to control for organisational characteristics such as firm age, firm size, ownership and industry, simply 'following the lead of previous academic studies' (e.g. Kaya 2006; Tang et al 2015, p. 1592), but ignore organisational design elements that structure human activity. Our study points to the utility of including a 'process-orientation' as an important source of variation in CE activities and outcomes across organisational units, and highlights the value of building into our theoretic models organisational antecedents to individual entrepreneurial behaviour other than those typically used. We believe, however, that the value of taking into account a process orientation extends beyond studies of CE to HRM more broadly. Formal business processes structure human activity, with high levels of business process maturity often seeking to secure 'person independence' by (intentionally) limiting discretionary behaviour and, as our study shows, (unintentionally) possibly motivation. The design and effects of formal business processes should thus be of keen interest to HR professionals and scholars beyond $\mathrm{CE}$, and it would likely benefit senior executives to encourage the involvement of HRM professionals in process design and implementation.

We theorised that formal business process-definitions are better suited to the exploitation activities of $\mathrm{CE}$, rather than exploration. The proposal that different human resource (HR) practices should be associated with exploration and exploitation is, in itself, not new. For example, although they did not explicitly address an organisational processorientation, Medcof and Song (2014) found that formal HR systems were better suited to exploitation than to exploration activities. However, we have gone beyond such studies by (1) identifying the differential impact of a process-orientation on exploration and exploitation in $\mathrm{CE}$; and (2) suggesting a more nuanced effect than in prior studies. In particular, we observe that even processes designed primarily for exploitation may have positive 'spillovers' for explorative activities by creating a context and mechanisms that foster knowledge exchange and the generation of novel knowledge recombinations, which may not readily occur otherwise. This differs markedly from prior studies that see systems of HR activities for 
exploration as different to, and distinct from, those suited to exploitation activities in CE (e.g. Medcof and Song 2014). While useful in simplifying complex reality, the creation of such sharp demarcations can also mask the subtle yet important interplay across systems of HR activities where each is designed for a specific purpose, and can thus lead to strategic blindspots (Leonard-Barton 1990).

We also extend current understandings of competencies for $\mathrm{CE}$ - both in relation to a process-oriented organisation and irrespective of this orientation. Building on our findings and theorisation around process-orientation and extending Hayton and Kelly's (2006) competencybased framework for promoting entrepreneurship, we have posited how the relative importance of a competency-based approach to assessing and deploying human capital varies across different aspects of CE (i.e. exploration and exploitation). That is, a competence-based approach is of greater importance to fostering explorative activity in CE than to exploitation activities, which are more amenable to being structured by formal business processes. We also identify decisiveness as an important dimension underlying a 'competence in sponsoring CE' (Hayton and Kelly 2006) more generally. It is this ability and willingness by executives to make a timely decision to support entrepreneurial ventures or initiatives that overcomes inertia. While recognised as an important element in individual entrepreneurship (Hisrich et al 2007; Miner 1997, 2002), decisiveness has somewhat surprisingly been hitherto overlooked as valuable in $\mathrm{CE}$. This is perhaps because the dominant approach to research on $\mathrm{CE}$ has been to focus on exemplars of successful $\mathrm{CE}$ - which creates a strong bias in cumulative findings (McGaughey 2013) - rather than what causes continuing inertia in low levels of CE or failure. The novel insights of this study are also partly attributable to the case study approach adopted. In our study, the first author's long employment with Siemens, concurrent with data collection, led to a deep intimacy with organisational history and practices, and access to internal networks. This valuable 'insider's perspective' was balanced by the critical 'outsider 
perspective' of the second author. Such 'researcher triangulation' enhances the likelihood of insights being generated that blend contributions to theory with practical relevance.

Case studies can convey meaning in a way other forms of scientific writing are less capable. Published case studies have long been acknowledged as one of the best ways for managers to develop judgement and analytical skills, including the evaluation of circumstances from multiple perspectives (Culpin and Scott 2012; Weil, Oyelere and Rainsburg 2004). They expose managers to real world complexity, particularly in relation to decision making (Gill 2014), and are valued in management education for pulling together theory, practice and the real world (Weil, Oyelere, Yeoh and Firer 2001). The verisimilitude - or life-likeness possible through a case study approach and verbatim quotes facilitates 'naturalistic generalisations'. These generalisations are 'arrived at by [the reader] recognizing the similarities of objects and issues in and out of context and sensing the natural covariations of happening' (Stake 1978, p. 6), and thus draws on prior knowledge of the reader. As highlighted in Table 2, our case study research captures real-world complexity in the relationship between strategic HRM activities and corporate entrepreneurship across a multiunit firm. Yet it also seeks to simplify this complexity and direct attention to essential elements previously under-theorised. In so doing, we hope to bridge and enrich theory and practice, and contribute to our growing understanding of the interplay between strategic HRM and corporate entrepreneurship in a multinational enterprise.

\section{References}

Alfoldi, E., Clegg, J. and McGaughey, S.L. (2012), Coordination at the Edge of the Empire: Subsidiary Regional Management Mandates in the Multinational Enterprise, Journal of International Management, 18: 276-92.

Alvarez, S.A., and Barney, J.B. (2005), 'How Do Entrepreneurs Organize Firms Under Conditions of Uncertainty?', Journal of Management, 31(5), 776-793.

Antoncic, B., and Hisrich, R.D. (2001), 'Intrapreneurship: Construct Refinement and Cross-cultural Validation', Journal of Business Venturing, 16(5), 495-527.

Benner, M. J., and Tushman, M. L. (2003). 'Exploitation, Exploration, and Process Management: The Productivity Dilemma Revisited.' Academy of Management Review, 2: 238-256. 
Birkinshaw, J., and Hood, N. (2001), 'Unleash Innovation in Foreign Subsidiaries', Harvard Business Review, 79(3), 131-137.

Block, Z., and Ornati, O.A. (1987), 'Compensating Corporate Venture Managers', Journal of Business Venturing, 2(1), 41-51.

Bowen, D.E. and Ostroff, C. (2004). 'Understanding HRM-firm Performance Linkages: The Role of the "Strength" of the HRM System'. The Academy of Management Review, 29(2), 203-221.

Brazeal, D.V. (1993). 'Organizing for Internally Developed Corporate Ventures', Journal of Business Venturing, 8(1), 75-90.

Brockhaus, R.H., Sr (1980), 'Risk Taking Propensity of Entrepreneurs', Academy of Management Journal, 23(3), 509-520.

Beugelsdijk, S. and Mudambi, R. (2013) 'MNEs as border-crossing multi-location enterprises: The role of discontinuities in geographic space', Journal of International Business Studies, 44(5): 413-426.

Chadwick, C., and Dabu, A. (2009), 'Human Resources, Human Resource Management, and the Competitive Advantage of Firms: Toward a More Comprehensive Model of Causal Linkages', Organization Science, 20(1), 253-272.

Chandler, G.N., Keller, C., and Lyon, D.W. (2000), 'Unraveling the Determinants and Consequences of an Innovation-supportive Organizational Culture', Entrepreneurship Theory and Practice, 25(1), 59-76.

Christensen, K.S. (2005), 'Enabling Intrapreneurship: The Case of a Knowledge-intensive Industrial Company', European Journal of Innovation Management, 8(3), 305-322.

Cromie, S., and O Donaghue, J. (1992), 'Research Note: Assessing Entrepreneurial Inclinations', International Small Business Journal, 10(2), 66-77.

Culpin, V. and Scott, H. (2012), 'The Effectiveness of a Live Case Study Approach: Increasing Knowledge and Understanding of 'Hard' Versus 'Soft' Skills in Executive Education,' Management Learning, 43(5), 565-577.

De Vos, A., and Dries, N. (2013), 'Applying a Talent Management Lens to Career Management: The Role of Human Capital Composition and Continuity', The International Journal of Human Resource Management, 24(9), 1816-1831.

Denzin, N.K. (1978), Sociological Methods: A Sourcebook, New York: McGraw-Hill.

Dess, G.G., Ireland, R.D., Zahra, S.A., Floyd, S.W., Janney, J.J., and Lane, P.J. (2003), 'Emerging Issues in Corporate Entrepreneurship', Journal of Management, 29(3), 351-378.

Dew, N. (2007), Abduction: A Pre-condition for the Intelligent Design of Strategy. The Journal of Business Strategy, 28(4): 38-45.

Eisenhardt, K.M. (1989), 'Making Fast Strategic Decisions in High-velocity Environments', The Academy of Management Journal, 32(3), 543-576.

Eisenhardt, K.M., and Graebner, M.E. (2007), 'Theory Building From Cases: Opportunities and Challenges', Academy of Management Journal, 50(1), 25-32.

Floyd, S.W., and Woolridge, B. (1999), 'Knowledge Creation and Social Networks in Corporate Entrepreneurship: The Renewal of Organizational Capability', Entrepreneurship Theory and Practice, 23(3), 123-143.

Fry, A. (1987), 'The Post-It Note: An Intrapreneurial Success', S.A.M. Advanced Management Journal, 52(3), 4-9.

Ghemawat, P. (2011), 'The Cosmopolitan Corporation', Harvard Business Review, 89, 92-99).

Gill, T.G. (2014), 'The Complexity and the Case Method,' Management Decision, 52(9), 15641590.

Glykas, M.M. (2011) 'Effort Based Performance Measurement in Business Process Management,' Knowledge and Process Management, 18(1): 10-33.

Guba E.G., and Lincoln Y.S. (1994), 'Competing Paradigms in Qualitative Research', in Handbook of qualitative research, eds. N.K. Denzin and Y.S. Lincoln, New York: SAGE Publications, pp. 105-117.

Gupta, A.K., Smith, K.G. and Shalley, C.E. (2006). 'The Interplay Between Exploration and Exploitation.' The Academy of Management Journal, 49(4): 693-706. 
Hayton, J.C. (2005), 'Promoting Corporate Entrepreneurship Through Human Resource Management Practices: A Review of Empirical Research', Human Resource Management Review, 15(1), 21-41.

Hayton, J. C. and Kelley, D. J. (2006). 'A Competency-Based Framework for Promoting Corporate Entrepreneurship.' Human Resource Management, 45(3): 407-427.

Hayton, J. C., Hornsby, J. S. and Bloodgood, J. (2013). 'Part II: The contribution of HRM to corporate: Entrepreneurship: A review and agenda for future research.' M@n@gement, 16(4): 381-409.

Haywood, M.L.A., Forster, W.R., Saravathy, S.D. and Frederikson, B.L. (2010) Beyond hubris: How highly confident entrepreneurs rebound to venture again. Journal of Business Venturing, 25: $569-578$.

Hedlund, G. (1994), 'A Model of Knowledge Management and the N-Form Corporation', Strategic Management Journal, 15(S2), 73-90.

Hisrich, R., Langan-Fox, J., and Grant, S. (2007), 'Entrepreneurship Research and Practice: A Call to Action for Psychology', American Psychologist, 62(6), 575-589.

Hornsby, J.S., Kuratko, D.F., and Montagno, R.V. (1999), 'Perception of Internal Factors for Corporate Entrepreneurship: A Comparison of Canadian and U.S. managers', Entrepreneurship Theory and Practice, 24(2), 9-24.

Ireland, R., Covin, J., and Kuratko, D. (2009), 'Conceptualizing Corporate Entrepreneurship Strategy', Entrepreneurship Theory and Practice, 33(1), 19-46.

Kaya, N. (2006), 'The Impact of Human Resource Management Practices and Corporate Entrepreneurship on Firm Performance: Evidence from Turkish Firms', International Journal of Human Resource Management, 17(12), 2074-2090.

Kohlbacher, M. (2010), 'The Effects of Process Orientation: A Literature Review', Business Process Management Journal, 16 (1), 135-152.

Kohlbacher, M. and Gruenwald, S. (2011), 'Process Orientation: Conceptualization and Measurement', Business Process Management Journal, 17(2): 267-283.

Kohlbacher, M. and Reijers, H.A. (2013) The effects of process-oriented organizational design on firm performance. Business Process Management Journal, 19(2): 245-262.

Kuratko, D. F., and Audretsch, D. B. (2009). 'Strategic entrepreneurship: Exploring different perspectives of an emerging concept'. Entrepreneurship Theory and Practice, 33(1): 1-17.

Kuratko, D. F., and Audretsch, D. B. (2013). 'Clarifying the Domains of Corporate Entrepreneurship'. International Entrepreneurship and Management Journal, 9(3): 323-35.

Kuratko, D.F., Hornsby, J.S., and Goldsby, M.G. (2004), 'Sustaining Corporate Entrepreneurship: Modelling Perceived Implementation and Outcome Comparisons at Organizational and Individual Levels', International Journal of Entrepreneurship and Innovation Management, $5(2), 77-89$.

Kuratko, D.F., Hornsby, J.S. and Hayton, J. (2015), 'Corporate entrepreneurship: the innovation challenge for a new global economic reality, 'Small Business Economics, DOI 10.1007/s11187015-9630-8.

Kuratko, D.F., Montagno, R.V., and Hornsby, J.S. (1990), 'Developing an Intrapreneurial Assessment Instrument for an Effective Corporate Entrepreneurial Environment', Strategic Management Journal (1986-1998), 11(5), 49-58.

Lepak, D.P., and Snell, S.A. (2002), 'Examining the Human Resource Architecture: The Relationships Among Human Capital, Employment, and Human Resource Configurations', Journal of Management, 28(4), 517-543.

Ling, Y., Simsek, Z., Lubatkin, M., and Veiga, J. (2008), 'Transformational Leadership's Role in Promoting Corporate Entrepreneurship: Examining the CEO-TMT Interface', Academy of Management Journal, 51(3), 557-576.

Lumpkin, G., Brigham, K., and Moss, T. (2010), 'Long-term Orientation: Implications for the Entrepreneurial Orientation and Performance of Family Businesses', Entrepreneurship and Regional Development, 22(3/4), 241-264.

MacMillan, I.C., and Day, D.L. (1987), 'Corporate Ventures into Industrial Markets: Dynamics of Aggressive Entry', Journal of Business Venturing, 2(1), 29-39. 
Mahnke, V., Venzin, M., and Zahra, S.A. (2007), 'Governing Entrepreneurial Opportunity Recognition in MNEs: Aligning Interests and Cognition Under Uncertainty', Journal of Management Studies, 44(7), 1278-1298.

March, J. G. 1991. 'Exploration and Exploitation in Organizational Learning.' Organization Science, 2: 71-87.

McGaughey, S.L. and Liesch, P.W. (2002) Management of the global sports-commerce nexus: The super league saga in Australia. Journal of Management Studies, 39(3): 383-416.

McGaughey, S.L. (2013). Institutional entrepreneurship in North American lightning protection standards: Rhetorical history and unintended consequences of failure. Business History, 55(1): 73-97

Medcof, J.W., and Song, L.J. (2013), 'Exploration, Exploitation and Human Resource Management Practices in Cooperative and Entrepreneurial HR Configurations', The International Journal of Human Resource Management, 24(15), 2911-2926.

Meili, E. (1990), My Life with Cerberus. Männedorf, Switzerland: Cerberus AG.

Menzel, H.C., Aaltio, I., and Ulijn, J.M. (2007), 'On the Way to Creativity: Engineers as Intrapreneurs in Organizations', Technovation, 27(12), 732-43.

Miles, M.B. and Huberman, A.M. (1994) 'An Expanded Sourcebook: Qualitative Data Analysis' ( $2^{\text {nd }}$ edition), Sage Publications, Thousand Oaks.

Miner, J.B. (1997), A Psychological Typology of Successful Entrepreneurs, Westport, CT: Quorum Books.

Miner, J.B. (2000), 'Testing a Psychological Typology of Entrepreneurship Using Business Founders', The Journal of Applied Behavioral Science, 36(1), 43-69.

Montoro-Sánchez, Á., and Domingo Ribeiro, S. (2011), 'Human Resource Management and Corporate Entrepreneurship', International Journal of Manpower, 32(1), 6-13.

Morse, J.M. (1994), 'Designing Funded Qualitative Research', in Handbook of Qualitative Research, eds. N.K. Denzin and Y.S. Lincoln, New York: SAGE Publications, pp. 220-235.

Nason, R.S., McKelvie, A. and Lumpkin, G.T. (2015),'The role of organizational size in the heterogeneous nature of corporate entrepreneurship', Small Business Economics. DOI $10.1007 / \mathrm{s} 11187-015-9632-6$

Patton, M.Q. (2005), Qualitative Research, Hoboken, N.J.: John Wiley \& Sons, Ltd.

Petrakis, P.E. (2005), 'Risk Perception, Risk Propensity and Entrepreneurial Behaviour: The Greek Case', Journal of American Academy of Business, Cambridge, 7(1), 233-242.

Phan, P.H., Wright, M., Ucbasaran, D. and Tan, W-L. (2009), Corporate entrepreneurship: Current research and future directions. Journal of Business Venturing, 24: 197-205.

Rohloff, M. (2011). 'Advances in Business Process Management Implementation Based on a Maturity Assessment and Best Practice Exchange'. Information Systems E-Business Management, 9: 383-403.

Roth, K. and Kostova, T. (2003), 'The use of multinational corporation as a Research Context', Journal of Management, 29(6), 883-902.

Schuler, R.S. (1986), 'Fostering and Facilitating Entrepreneurship in Organizations: Implications for Organization Structure and Human Resource Management Practices', Human Resource Management (1986-1998), 25(4), 607-629.

Sharma, P., and Chrisman, J.J. (1999), 'Toward a Reconciliation of the Definitional Issues in the Field of Corporate Entrepreneurship', Entrepreneurship Theory and Practice, 23(3), 11.

Stake, R.E. (1978), 'The Case Study Method in Social Inquiry'. Educational Researcher, 7(2): 5-8.

Stake, R.E. (1995), The Art of Case Study Research, London: SAGE Publications.

Sykes, H.B. (1992), 'Incentive Compensation for Corporate Venture Personnel', Journal of Business Venturing, 7(4), 253-265.

Tang, G., Wei, L-Q., Snape, E. and Ng, Y.C. (2015) 'How Effective Human Resource Management Promotes Corporate Entrepreneurship: Evidence from China.' The International Journal of Human Resource Management, 26(12), 1586-1601.

Teece, D. J., G. Pisano, A. Shuen. (1997), 'Dynamic Capabilities and Strategic Management.' Strategic Management Journal. 18(7): 509-533. 
Weil, S. Oyelere, P. and Rainsburg, E. (2004), The Usefulness of Case Studies in Developing Core Competencies in a Professional Accounting Programme: A New Zealand Case Study.' Accounting Education 13(2), 139-169.

Weil, S. Oyelere, P. Yeoh, J. and Firer, C. (2001), A study of students' perceptions of the usefulness of case studies for the development of finance and accounting-related skills and knowledge. Accounting Education 10(2): 123-146.

Welch, C., and Piekkari, R. (2006), 'Crossing Language Boundaries: Qualitative Interviewing in International Business', Management International Review, 46(4), 417-437.

Wright, P.M. and McMahan, G.C. (2011), 'Exploring Human Capital: Putting Human Back into Strategic Human Resource Mangement.' Human Resource Management Journal, 21(2): 93-104. Wright, P.M. and McMahan, G.C. (1992), Theoretical Perspectives on Strategic Human Resource Management. Journal of Management, 18(2): 295-320.

Wright, P.M., Dunford, B.B. and Snell, S.A. (2001), 'Human Resources and the Resource Based View of the Firm,' Journal of Management, 27(6): 701-721.

Yin, R.K. (2009), Case Study Research: Design and Methods, New York: SAGE Publications. 
Table 1: Case-specific data sources

\begin{tabular}{|c|c|c|c|c|c|}
\hline \multirow{2}{*}{\multicolumn{2}{|c|}{$\begin{array}{l}\text { Organisations } \\
\text { and roles }\end{array}$}} & \multicolumn{3}{|c|}{ Interviewees by cases } & \multirow{3}{*}{\begin{tabular}{|l|}
\multicolumn{1}{|c}{$\begin{array}{c}\text { Siemens AG } \\
\text { corporate } \\
\text { perspective }\end{array}$} \\
alobal Project \\
Lead SMART \\
Initiative
\end{tabular}} \\
\hline & & $\begin{array}{c}\text { Case } 1 \\
\text { Shinwha acquisition }\end{array}$ & $\begin{array}{c}\text { Cases } 2 \\
\text { SMART project }\end{array}$ & $\begin{array}{c}\text { Case } 3 \\
\text { SP new setup }\end{array}$ & \\
\hline \multirow{3}{*}{ 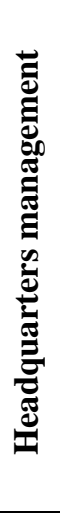 } & $\mathrm{CEO} / \mathrm{PL}$ & \multicolumn{3}{|c|}{-CEO BT FS } & \\
\hline & $\begin{array}{l}\text { R\&D, PM, } \\
\text { Sales }\end{array}$ & $\begin{array}{l}\text {-Regional Manager for } \\
\text { Korea in FS HQ }\end{array}$ & $\begin{array}{l}\text { qGlobal Head of } \\
\text { FS SES }\end{array}$ & $\begin{array}{l}\text {-Integration } \\
\text { Manager iMetrex; } \\
\text { nGlobal Head of } \\
\text { Product Line } \\
\text { Intrusion (before SP } \\
\text { new setup) }\end{array}$ & \\
\hline & HRM & \multicolumn{3}{|c|}{-Global Head of FS Human Resources } & $\begin{array}{c}\text {-Management } \\
\text { Development HQ }\end{array}$ \\
\hline \multirow{3}{*}{ 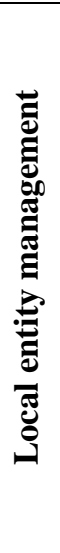 } & $\begin{array}{l}\mathrm{CEO} / \mathrm{CFO} / \\
\mathrm{PL}\end{array}$ & 口CFO BT Korea & $\begin{array}{l}\text { qGlobal Head FS } \\
\text { SYS }\end{array}$ & $\begin{array}{l}\text {-CEO SP new } \\
\text { setup }\end{array}$ & \\
\hline & $\begin{array}{l}\text { former } \\
\mathrm{CEO} / \mathrm{CFO}\end{array}$ & $\begin{array}{l}\text {-CEO BT Korea. } \\
\text {-CEO of Shinwha and } \\
\text { CEO, Shinwha Siemens }\end{array}$ & & $\begin{array}{l}\text {-Chief Marketing } \\
\text { Officer BT }\end{array}$ & \\
\hline & $\begin{array}{l}\text { R\&D, PM, } \\
\text { Sales }\end{array}$ & $\begin{array}{l}\text {-Head of R\&D and } \\
\text { Manufacturing at FS } \\
\text { Korea; } \\
\text {-Head of BT FS Korea } \\
\text { and former CEO of } \\
\text { Shinwha Fire } \\
\text { Protection }\end{array}$ & $\begin{array}{l}\text {-Head of Product } \\
\text { Management FS } \\
\text { China; } \\
\text {-Regional } \\
\text { Coordinator for } \\
\text { Korea and China }\end{array}$ & $\begin{array}{l}\text {-Head of Product } \\
\text { Line within SP } \\
\text { new setup }\end{array}$ & \\
\hline
\end{tabular}

\begin{tabular}{|l|c|c|}
\hline \multirow{3}{*}{ Primary Data } & financial reports (monthly, quarterly, yearly) \\
\cline { 2 - 3 } & project planning and reports & \\
\cline { 2 - 3 } & employee surveys & \\
\cline { 2 - 3 } & management reports & \\
\hline
\end{tabular}

Legend: $\mathrm{PL}=$ project lead, $\mathrm{PM}=$ product management, $\mathrm{HRM}=$ human resource management, $\mathrm{R} \& \mathrm{D}=$ Research and Development, $\mathrm{CEO}=$ chief executive officer, $\mathrm{CFO}=$ chief financial officer, $\mathrm{BT}=$ Building Technologies, FS = Fire Safety, SMART = simple, maintenance-friendly, affordable, reliable and timely, $\mathrm{SP}=$ security products, $\mathrm{HQ}=$ Siemens AG Corporate Headquarters, SES = Security Solutions 


\section{Supporting entrepreneurial rents (Chadwick and Dabu 2009)}

Acquisition. Selection favours workers with a taste for entrepreneurial knowledge sharing. Preference is also given to individuals with requisite entrepreneurial capital, such as social networks or knowledge in specific areas of need. To the degree that spontaneous entrepreneurship is favoured within the firm, hiring decisions can be decentralised and based on locally perceived needs for specific entrepreneurial human capital.

Retention. The value of retention varies across workers and circumstances.

Turnover can be detrimental to entrepreneurship when valuable knowledge is lost, but it can also substitute new workers with valuable entrepreneurial capital for workers whose entrepreneurial value is negligible or redundant. However, because managerial entrepreneurship has strong firm specificity, retention is generally desirable.

\section{Siemens case study findings - positive $(\checkmark)$ and negative impacts of HRM activities on CE $(x)$}

$\times$ Hiring decisions for key appointments are centralised and favour internal, German executives (associated with higher levels of risk aversion) due to rotations in Top Talent career model

$\times \mathrm{CE}$ capabilities (e.g. in corporate venturing, risk taking) are not part of selection criteria in the Siemens Leadership Framework

$x$ Process orientation aims at 'person independence', thereby potentially discounting the importance of competencies underpinning entrepreneurial initiative and judgement

$\checkmark$ Stable cadre of 'top talent' expatriates transfers knowledge, but...

$\times 2-3$ year executive stays, reinforced by career model, undermine development of valuable domain knowledge deemed important to successful knowledge recombinations and exploration of entrepreneurial opportunity

×Short stays undermine clan communications

$\times$ Short stays promote short-term orientation to performance management, thereby undermining the long-term orientation needed for $\mathrm{CE}$
Support for (+) and extensions to (++) Chadwick and Dabu (2009)

+Selection by whom? Empower local divisions to have greater say in selection for $\mathrm{CE}$

++ Include selection criteria that capture key entrepreneurial characteristics beyond knowledge sharing (e.g. risk taking, decisiveness)

++ Recognise distinct capabilities required for opportunity exploration and opportunity exploitation, providing dedicated teams with appropriately differentiated selection criteria to foster organisational ambidexterity perceived necessary for $\mathrm{CE}$

++ Encourage external recruitment within a knowledge domain (e.g. industry) to strengthen infusion and recombinations of knowledge

+Retention enhances development of deep domain knowledge ++ Duration in an assignment or role should enable measurement of outcomes over a longer time horizon to capture CE outcomes; that is, a longer-term orientation is required. However, definitions of 'long-term' are specific to industry product life-cycles. 
Supporting entrepreneurial rents (Chadwick and Dabu 2009)

Training. Because the focus is on innovation, training [...] focusses on interpersonal skills and group processes that facilitate workers' ability to aggregate their localised knowledge into entrepreneurial innovations. be foreseen by management, motivation in entrepreneurial rents favours practices that build up incentives for workers to exercise discretionary effort in entrepreneurship, rewarding outcomes rather than conformity to managementspecified processes. Motivation is often in the form of ownership.

\section{Coordination/ deployment.}

Entrepreneurial rents also require complex and idiosyncratic coordination and deployment mechanisms, but these concern the generation and exploitation of knowledge held by the unique community of actors constituting the firm
Siemens case study findings - positive $(\checkmark)$ and negative impacts of HRM activities on CE (x)

$\checkmark$ Siemens Leadership Framework builds social capital among units. Junior executives have mentorship with senior executives across units

$x$ Cultural sensitivity has a low profile in the leadership framework

x Primarily inward focussed - understanding of transfer of key elements in external environment (e.g. customer needs and relationships) not developed
Support for (+) and extensions to (++) Chadwick and Dabu (2009)

++ Training required to develop skills in not only aggregating local (domain) knowledge, but also effectively acquiring it

++ Cross cultural training that facilitates inter-cultural team work is essential to enhance the potential to identify and recombine knowledge acquired across borders into new configurations
xPerformance measures over short time horizon, perceived to undermine the building of new business sustainable in the longer term

$\times$ Risk averse culture with low levels of forgiveness for failure, little discretion/ empowerment and a lack of decisiveness are perceived, undermining motivation

? Incentives to share information

$\checkmark$ Recognition through subsidiary and expert certification is an important form of reward that grants autonomy and thus increases motivation

$\checkmark$ Development of process definitions that align employees' behaviours with objectives of the firm, seeking to reduce 'person dependence'

$\checkmark$ Processes aligned to the exploitation of technical innovations (inward focus is strong)

$x$ Processes not aligned to customers, leading to poor exploration and failure to transfer knowledge of customer networks and knowledge (Outward focus lacking)

$\checkmark$ Ad hoc initiatives to set up explorative teams outside formal processes through 'clans'
+Clearly defined reward system, but challenge lies more in a definition of entrepreneurial goals and desired behaviour ++ Organisational culture that displays tolerance of failure, entrepreneurial risk

++ Measure outcomes over a longer time horizon to capture entrepreneurial/ business-building outcomes and provide disincentives for overly self-interested 'career-making'

++ Provision of autonomy for earned Certification by subsidiaries and experts; increasing 'person dependence' - but more assured of the 'right' person

++ Develop distinct teams for opportunity identification and exploitation (see acquisition and selection criteria above). That is, there may be different communities and clan structures within the firm

++ Develop process definitions to support leveraging knowledge possessed and opportunities identified by those outside the firm 
A - Reference model (adapted from Kuratko, Hornsby and Goldsby

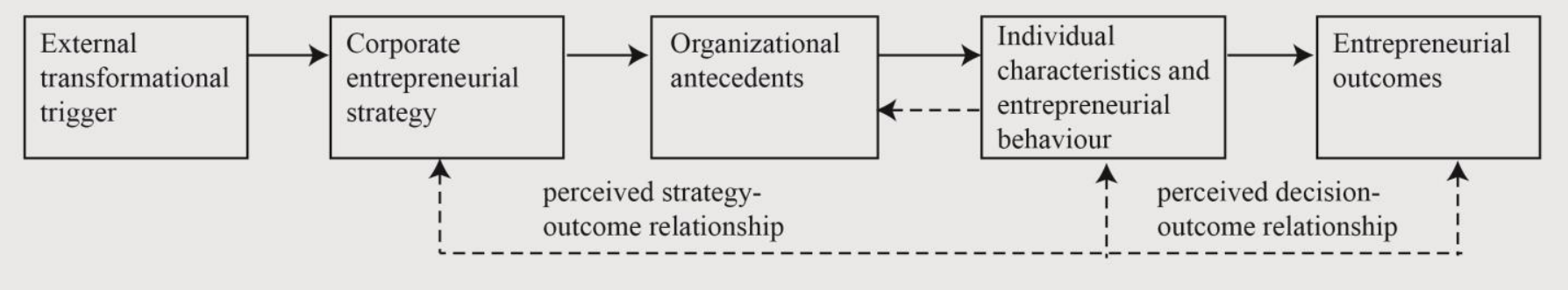

\section{B - Study findings}

Fire Safety:

Investment goods,

slow paced

innovations, in

global

consolidation,

primarily based on

installed base of

its own products

Security Products: Investment goods, medium to fast paced innovations, manuy players on global and local markets

,

Strategy is primarily focussed on incremental technical innovations, going for organic growth in existing business segments and markets

$$
\begin{aligned}
& \mathbf{1} \\
& 1 \\
& 1 \\
& 1 \\
& 1 \\
& 1 \\
& 1 \\
& 1 \\
& 1 \\
& 1 \\
& 1 \\
& 1 \\
& 1 \\
& 1 \\
& 1 \\
& 1
\end{aligned}
$$

Key Elements

Process orientation *person independence *internal focus of mature processes

Siemens Leadership

Framework

*selection criteria

Top Talent Career

Concept

*German dominance in

top managment

Short-term rotations

* Short-term incentive

structures

Organisational Mileau

*short-term planning

context

*missing 'forgiveness

of failure'

*missing empowerment
Key Elements

* discretionary CE

behaviours

constrained

*opportunity

exploration internally

focussed

*weak competencies

for $\mathrm{CE}$

*risk aversion

* Weak knowledge

acquisition and

recombinations

*Career-making

behaviours that

neglect long-term

business building

*indecisiveness
Fires Safety:

lost market leader position in recent years by loosing out against existing competitors

Security Products: Failed business, in careve-out

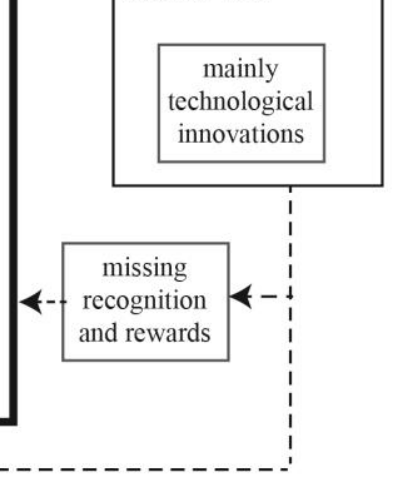

Figure 1: Organisational antecedents and the entrepreneurial behaviour of individuals 